\title{
Estudio de la satisfacción de un objeto de aprendizaje para la enseñanza del temaequilibrio ácido-base en la licenciatura de Medicina
}

Study about the satisfaction regarding a learning object for the teaching of the theme acid-base equilibrium in the bachelorof Medical School

Estudo da satisfação de um objeto de aprendizagem para o ensino da disciplina equilíbrio ácido-básico em Bacharel em medicina

Claudia Zepeda Cortés

Benemérita Universidad Autónoma de Puebla, Facultad de Ciencias de la Computación,

México

czepedac@gmail.com

https://orcid.org/0000-0002-2208-7691

Ana Patricia Cervantes Márquez

Benemérita Universidad Autónoma de Puebla, Facultad de Ciencias de la Computación,

México

cervantes.patty@gmail.com https://orcid.org/0000-0002-4246-102X

Hilda Castillo Zacatelco

Benemérita Universidad Autónoma de Puebla, Facultad de Ciencias de la Computación,

México

hildacz@gmail.com

https://orcid.org/0000-0001-5381-441X 


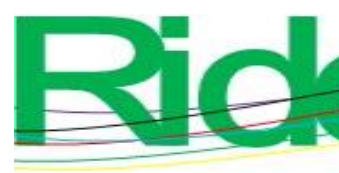
Revista Iberoamericana para la
Investigación y el Desarrollo Educativo
ISSN $2007-7467$

Autónoma de Puebla,durante el semestre de otoño de 2019. Los resultados documentan un grado de satisfacción alto y señalan áreas de oportunidad para producir objetos de aprendizaje similares.

Palabras clave:bioquímica, pH,satisfacción, usabilidad.

\begin{abstract}
The $\mathrm{pH}$ in the human body is of vital importance for its proper functioning, an imbalance in it can cause serious health problems and even death. This topic is addressed in the first Biochemistry course of the Bachelor of Medicine in all universities and has always shown a high degree of difficulty, consequently, the failure rate is high. To support the attention to this problem, previous works describe the design and development of a Learning Object for this topic, emphasizing its importance and at the same time, seeking to influence the increase in the approval rate. This work describes the methodology that was followed to carry out a study of the satisfaction of this Learning Object, whose contents are presented in three videos. Students from nine sections of the first Biochemistry course from the first semester of the Faculty of Medicine of the Benemérita Universidad Autónoma de Puebla participated in the study, which was carried out during the fall semester of 2019. The results document a high degree of satisfaction and indicate areas of opportunity to produce similar learning objects.
\end{abstract}

Keywords:Biochemistry, $\mathrm{pH}$, satisfaction, usability.

\title{
Resumo
}

O pH do corpo humano é de vital importância para o seubomfuncionamento, poisumdesequilíbrio no mesmo pode causar sérios problemas de saúde e até a morte. Esta disciplina é abordada no curso de Bioquímica I do curso de Medicina de todas as universidades e sempreapresentouum alto grau de dificuldade, logo o índice de reprovação é alto. Para apoiar a atenção a este problema, trabalhos anteriores descrevem o projeto e desenvolvimento de um objeto de aprendizagem para este tópico, enfatizando suaimportância. Por outro lado, nestetrabalho, é descrita a metodologia que foi seguida para realizar umestudo da satisfaçãodeste objeto de aprendizagem, cujosconteúdosforamapresentados em três vídeos. Alunos de nove cursos de Bioquímica I 


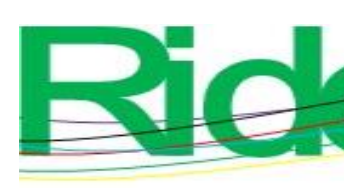

Revista Iberoamericana para la
Investigación y el Desarrollo Educativo
ISSN $2007-7467$

El tema equilibrioácido-base considera principalmente al $\mathrm{pH}$, el cual es una unidad de medida del grado de acidez o basicidad de una sustancia (sus valores oscilan entre 0 y 14, siendo 7 su estado de neutralidad). El cuerpo humano contiene muchas sustancias ácidas y básicas, obtenidas de forma endógena y exógena, las cuales al mantenerse en equilibrio favorecen su funcionamiento correcto. Los ácidos son sustancias que al disociarse pierden iones $\left(\mathrm{H}^{+}\right)$y las bases son sustancias capaces de aceptarlos. El mantenimiento del pH resulta esencial, ya que afecta la ionización de las proteínas y, en consecuencia, la actividad de muchas enzimas. La regulación del pH extra e intracelular está estrechamente relacionada con el intercambio de gases y este último, más el equilibrio ácido base, al sufrir alteraciones ocasionan una variedad de enfermedades de los sistemas renal y respiratorio.

El OA-EABha sido implementado según la metodología deCodaes(Codaeses un proyecto realizado con financiamiento de la Secretaría de Educación Pública-Subsecretaría de Educación Superior-Dirección General de Educación Superior Universitaria en México). Losautores de este documento cuentan con experiencia utilizando la plataforma de Codaes, donde también han participado en el desarrollo de otros OA.

Se considera que el soporte que ofrecen para el desarrollo de OA y el servicio que otorgan es adecuado para la población estudiantil a la que se quiere impactar. Cabe resaltar que los responsables de la plataforma Codaessiempre tienen disponibilidad para escuchar propuestas que permitan mejorar la plataforma.

Actualmente, el OA-EABse encuentra en la última etapa antes de que esté disponible en el portal Codaes, lo que significa que está siendo evaluado. Es importante mencionar que el OA-EABse desarrolló conforme a una metodología validada, integrada por diferentes etapas y que cada una se ha evaluado por miembros y expertos de la comunidad.El diseño y desarrollo del OA-EAB se describe en Castilloet al. (2019) y un resumen de esto se presenta en la siguiente sección.

La usabilidad es un aspecto a evaluar en los OA, pues permite alcanzar objetivos específicos con usuarios definidos en un contexto de uso concreto, y se relaciona - entre otros aspectos - con la satisfacción de los participantes una vez que han empleado el OA. En este documento se presenta la metodología que se siguió durante la implementación de un estudiopara evaluar la satisfacción y los resultadosconseguidoscon estudiantes de nueve cursos de Bioquímica I (del primer semestre de la Facultad de Medicina de la BUAP en 

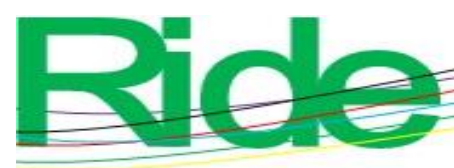

Revista Iberoamericana para la Investigación y el Desarrollo Educativo ISSN 2007 - 7467

Vale destacar que una de las tareas más importanteslograda, mediante la colaboración de todos los participantes, fue la construcción de losguiones gráficos(muchas veces conocidos como storyboards). Estos son la base para la construcción de los videos asociados a cada uno de los subtemas, ya que son los que indican qué debe presentarse y escucharse, además de cuándo y cómo. A manera de ejemplos, la figura 1 muestra dos guiones gráficos creados para uno de los subtemas.

Figura 1. Guiones gráficos del subtema de introducción del OA-EAB
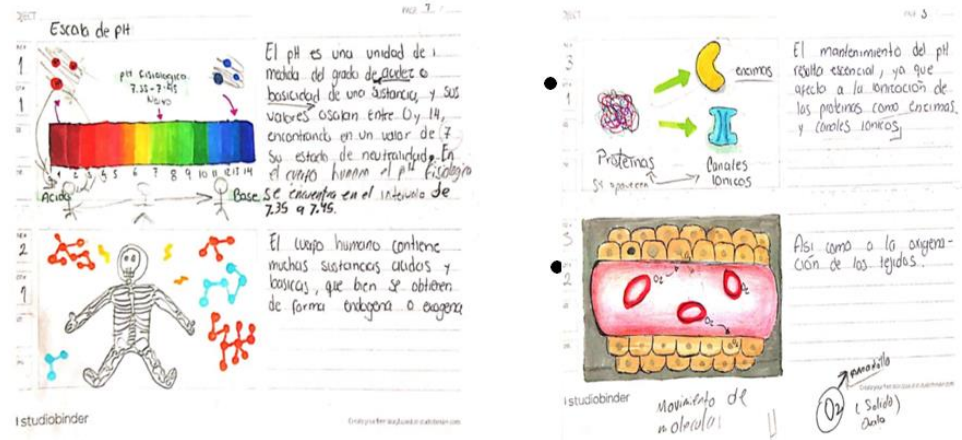

Fuente: Elaboración propia

En aspectos de diseño, se lograron acuerdos para obtener una apariencia homogénea en los videos en cuanto a colores, formas e imágenes. Además, se construyó una plantilla para el tipo, color y tamaño de letra, márgenes, colores de fondo, sangrías y uso de audio. La mayor parte de las imágenes son propias, es decir, los estudiantes de la FCC-BUAP las construyeron con base en las indicaciones de profesores y estudiantes de la FM-BUAP; las restantes se distribuyen bajo términos de políticas de acceso abierto. En la figura 2 se observa una captura de pantalla que muestra la parte inferior del segundo guión gráfico de la figura 1 (esta se obtuvo al visualizar el video de uno de los subtemas del tema equilibrio ácido-base). 


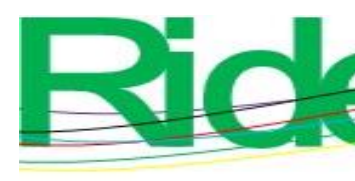

Revista Iberoamericana para la Investigación y el Desarrollo Educativo ISSN 2007-7467

\section{Actividades de autoevaluación del OA-EAB}

Las actividades de autoevaluación del OA-EABfueron implementadas utilizando Educaplay, plataforma diseñadapara crear y encontrar actividades educativas, gestionar grupos, exportar recursos (es adaptable al tamaño de la pantalla de cualquier dispositivo, disponible enhttps://es.educaplay.com/). Las actividades para los videos 1 y 3 consisten en un crucigrama de ocho y uno de cinco palabras que se refieren a los conceptos básicos del tema equilibrio ácido-base en el primero, y alteraciones en el segundo.Los crucigramascuentan con pistas que ayudan a encontrar la solución y los estudiantes pueden realizar cada crucigramalas veces que deseen; además, pueden conocer su progreso a través de un puntaje, así como observar la solución correcta (cabe destacar que no se asignó un límite de repeticiones).

Por otro lado, la actividad de autoevaluación del video 2 consiste en relacionar columnas acerca de diez conceptos relevantes del tema amortiguadores, para lo que se asignó un tiempo límite de dos minutos. Al finalizar el intento o al exceder el tiempo límite, se muestra el resultado con el puntaje obtenido y la solución correcta; también se ofrece la opción de volver a intentar sin exceder el máximo de intentos (15 intentos).

\section{Usabilidad y satisfacción}

Formalmente, las definiciones de usabilidad, de acuerdo con la Organización Internacional para la Estandarización (ISO), sonlas siguientes(ISO 9241-11): a) "La usabilidad se refiere a la capacidad de un software de ser comprendido, aprendido, usado y ser atractivo para el usuario, en condiciones específicas de uso" y b) la "usabilidad es la eficacia, eficiencia y satisfacción con la que un producto permite alcanzar objetivos específicos a usuarios específicos en un contexto de uso específico”. La usabilidad es un aspecto a evaluar en los OA, y se relaciona con elementos como la facilidad de navegación, la calidad de los recursos de ayuda en una interfaz y la capacidad de predicción de acciones y eventos.

Cuando la usabilidad se percibe como un proceso, la eficiencia, la eficacia y la satisfacción se asocian con la recolección de datos,interpretada comoinformación desde un enfoque cuantitativo que emplea un conjunto de métricas, o con un enfoque cualitativo que resalta la experiencia de los expertos y las opiniones de los usuarios, así como utilizando un enfoque mixto de acuerdo con los intereses y elementos que se desean evaluar 


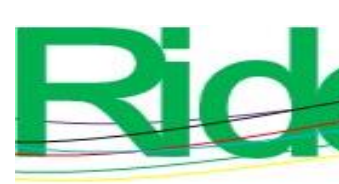

Revista Iberoamericana para la
Investigación y el Desarrollo Educativo ISSN $2007-7467$

(González,Montero y Gutiérrez,2012); por ejemplo, considerar la tasa de escala de satisfacción, la tasa de uso en el tiempo o la frecuencia de quejas como métricas que se asocian con la satisfacción.

\section{Metodología y resultados}

Como se refirió en la introducción de este documento, el OA-EAB se desarrollópara apoyar en las necesidades de formación de los futuros estudiantes de la asignatura de Bioquímica I en la FM-BUAP. Uno de los aspectos a evaluar en cualquier OA es su usabilidad.Como se mencionó en la sección anterior, la usabilidad permite alcanzar objetivos específicos según usuarios concretos en un contexto determinado, lo que se relaciona — entre otros aspectos_ con la satisfacción de los usuarios luego de emplear el OA.

Precisado esto, en esta sección se describe la metodología que se siguió durante la implementación de un estudio para evaluar la satisfacciónde estudiantes de nueve cursos de Bioquímica I del primer semestre de la FM-BUAP en otoño de 2019, quienes utilizaron los videosde cada subtema incluido en el OA-EAB y los resultados obtenidos.El propósitofuecontar con una valoración de la satisfacción de cada video, previa a la liberación del OA-EAB en la plataforma Codaes.

\section{Descripción de estudiantes}

La tabla 2muestra el número y género de losestudiantes que participaron en la evaluación de satisfacción de cada video (ver tabla 1).Al respecto, cabe resaltar que algunos estudiantes no visualizaron todos los videos; sin embargo, todos pertenecen a los nueve grupos de estudiantes de los 21 grupos de primer semestre que cursaron la asignatura Bioquímica I.Las edades de los estudiantes oscilan entre los 18y 21 años. La evaluación se realizó durante el semestre de otoño 2019 en la Facultad de Medicina de la BUAP (el periodo de evaluación fue de cinco días hábiles). 


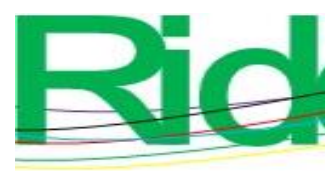

2

Tabla 3. Lista de verificación valores promedio de satisfacción de los tres videos

\begin{tabular}{|c|c|c|c|}
\hline No. & Aspecto de verificación & Cumple & $\begin{array}{c}\text { No } \\
\text { cumple }\end{array}$ \\
\hline 1 & El video fue fácil de encontrar & & \\
\hline 2 & El video se cargó rápidamente & & \\
\hline 3 & El video estuvo disponible & & \\
\hline 4 & Fue fácil llegar a cualquier parte del video & & \\
\hline 5 & La información del video estuvo organizada & & \\
\hline 6 & La información del video fue veraz & & \\
\hline 7 & $\begin{array}{l}\text { El nivel de dificultad de los contenidos fue } \\
\text { apropiado }\end{array}$ & & \\
\hline 8 & $\begin{array}{l}\text { La estética (colores utilizados, tipo de letra, } \\
\text { colocación de los elementos gráficos) fue } \\
\text { adecuada }\end{array}$ & & \\
\hline 9 & $\begin{array}{l}\text { La información presentada fue adecuada y } \\
\text { suficiente }\end{array}$ & & \\
\hline 10 & El video me ayudó a aprender & & \\
\hline
\end{tabular}

Fuente: Elaboración propia

\section{Actividad 2. Diseño y aplicación de instrumento de evaluación diagnóstica}

Los profesores de la FM-BUAP diseñaron un instrumento de evaluación diagnóstica para obtener información sobre los conocimientos previos de los estudiantes acerca del tema equilibrio ácido-base.Antes de que los profesores expusieran el tema en los grupos, entregaron a los estudiantes el instrumento de evaluación diagnóstica en forma impresa para que lo contestaran en15 minutos como máximo. Un fragmento del instrumento se muestra en la figura 3. 
Figura 3. Fragmento del instrumento de evaluación

\begin{tabular}{|c|}
\hline DEPARTAMENTO-DEBIOQUIMICA.FM-BUAPT \\
\hline 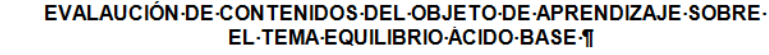 \\
\hline INSTRUCCIÓN: subraya ła-respuesta correcta-a-las siguientes preguntas. đI \\
\hline 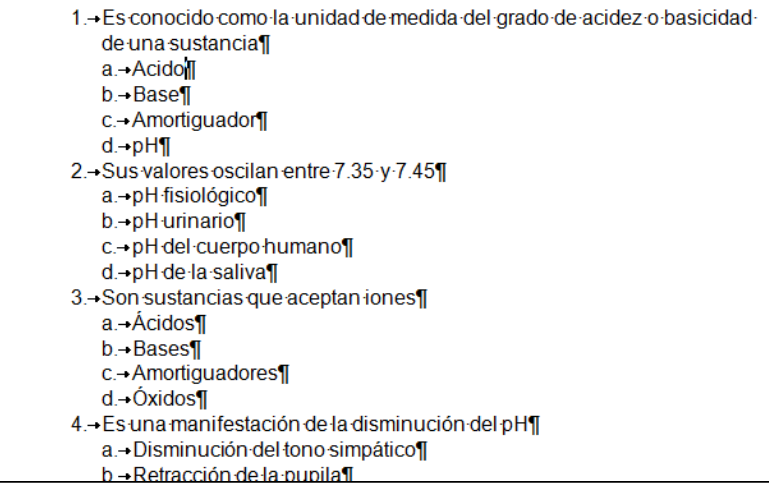 \\
\hline
\end{tabular}

Fuente: Elaboración propia

\section{Actividad 3. Seguimiento de instrucciones}

El mismo día de clase que fue entregado el instrumento de evaluación diagnósticay posterior a haberlo recolectado ya contestado, cada profesor escribió sobre el pizarrón la dirección en internetpara acceder a los videos y a los enlaces para los instrumentos de evaluación de satisfacción. Acto seguido, cada profesor indicó que tenían un máximo de tres días para revisarlos tres videos(se buscó que esos días coincidieran con el fin de semana, es decir, días en los que no hay clases) para que respondieran los instrumentos de evaluación de satisfacción correspondientes, aunque algunos alumnos-como se muestra en la figura 4- comenzaron de forma inmediata a visualizar los videos.

Figura 4. Visualización de videos por estudiantes de la FM

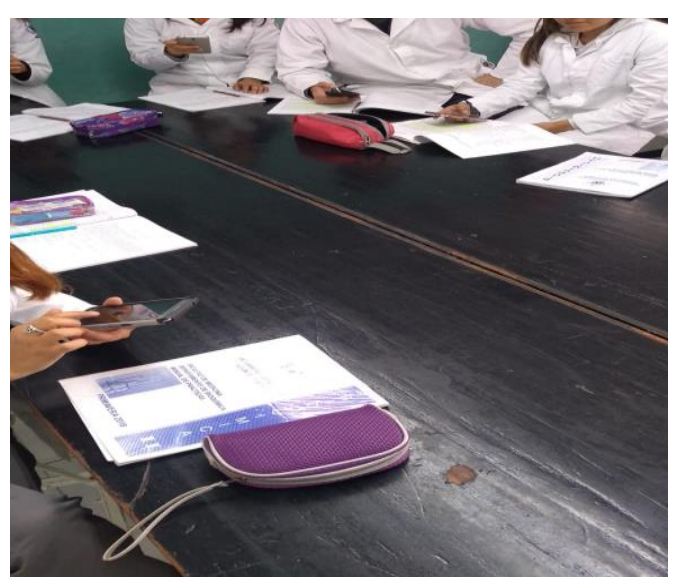

Fuente: Elaboración propia 
Sección 1.Presenta el título y subtítulo del video.

Sección 2.Recolecta la siguiente información personal delos estudiantes: número de matrícula, nombre completo y número de sección del curso. Junto con la información personal - la cual se emplea bajo criterios de confidencialidad y únicamente para el análisis de resultados-, en la sección 2también se insertó una pregunta en la que se pide a los estudiantes indicar cómo consideran que aprenden más fácilmente:"escuchando", "viendo" y "haciendo"(palabras asociadas con los estilos de aprendizaje auditivo, visual o kinestésico, respectivamente).

Sección 3.Contiene el cuestionario de diezpreguntas que muestra la tabla 4.

Tabla 4. Cuestionario de la sección 3: instrumento de evaluación de satisfacción

\begin{tabular}{|c|c|}
\hline $\begin{array}{c}\text { Pregunt } \\
\text { a }\end{array}$ & Descripción \\
\hline 1 & $\begin{array}{l}\text { ¿Considera que la cantidad de información que se incluye en el video es } \\
\text { demasiada? }\end{array}$ \\
\hline 2 & $\begin{array}{l}\text { ¿Piensa que existe una adecuada relación entre el audio, las imágenes y el } \\
\text { texto presentado? }\end{array}$ \\
\hline 3 & ¿Los textos resultan fácilmente legibles? \\
\hline 4 & ¿Las imágenes y animaciones presentadas son de buena calidad? \\
\hline 5 & ¿El video expone los temas a una velocidad adecuada? \\
\hline 6 & ¿La pronunciación y entonación es entendible? \\
\hline 7 & ¿Considera que los efectos de sonido se están utilizando adecuadamente? \\
\hline 8 & ¿Considera que hay silencios incómodos durante la exposición del video? \\
\hline 9 & $\begin{array}{l}\text { ¿Le gustaría contar con más videos que le apoyen con otros temas de este } \\
\text { curso? }\end{array}$ \\
\hline 10 & ¿Compartiría este video con alguien? \\
\hline
\end{tabular}

Fuente: Elaboración propia

En las instrucciones del cuestionario, se solicitó a los estudiantes contestar cada pregunta a través de la selección de uno de los cinco valores de la escala de Likert siguiente(los valores se presentan con una orientación de lo negativo a lo positivo):

- Totalmente en desacuerdo (1)

- En desacuerdo (2)

- Ni de acuerdo ni en desacuerdo (3)

- De acuerdo (4) y

- Totalmente de acuerdo (5)

La tabla 5enseñalos promedios obtenidos en la evaluación de satisfacción del video1: introducción. 
Tabla 8. Valores promedio de satisfacción de los tres videos

\begin{tabular}{|c|c|c|c|c|c|}
\hline \multirow[b]{2}{*}{ Pregunta } & \multicolumn{4}{|c|}{ Promedio del video } & \multirow{2}{*}{$\begin{array}{l}\text { En la escala } \\
\text { Likert es más } \\
\text { cercano a }\end{array}$} \\
\hline & 1 & 2 & 3 & $\begin{array}{c}\text { de los } \\
3\end{array}$ & \\
\hline $\begin{array}{l}\text { 1. ¿Considera que la cantidad de } \\
\text { información que se incluye en el video } \\
\text { es demasiada? }\end{array}$ & 2.3 & 2.5 & 2.2 & 2.3 & En desacuerdo \\
\hline $\begin{array}{l}\text { 2. ¿Piensa que existe una adecuada } \\
\text { relación entre el audio, las imágenes y } \\
\text { el texto presentado? }\end{array}$ & 4.2 & 4.1 & 3.7 & 4 & De acuerdo \\
\hline $\begin{array}{l}\text { 3. ¿Los textos resultan fácilmente } \\
\text { legibles? }\end{array}$ & 4.3 & 4.2 & 3.7 & 4 & De acuerdo \\
\hline $\begin{array}{l}\text { 4. ¿Las imágenes y animaciones } \\
\text { presentadas son de buena calidad? }\end{array}$ & 4.1 & 4.1 & 3.7 & 3.9 & De acuerdo \\
\hline $\begin{array}{l}\text { 5. ¿El video expone los temas a una } \\
\text { velocidad adecuada? }\end{array}$ & 3.9 & 3.7 & 3.3 & 3.6 & De acuerdo \\
\hline $\begin{array}{l}\text { 6. ¿La pronunciación y entonación es } \\
\text { entendible? }\end{array}$ & 3.8 & 3.7 & 3.3 & 3.6 & De acuerdo \\
\hline $\begin{array}{l}\text { 7. ¿Considera que los efectos de } \\
\text { sonido se están utilizando } \\
\text { adecuadamente? }\end{array}$ & 3.8 & 3.9 & 3.4 & 3.7 & De acuerdo \\
\hline $\begin{array}{l}\text { 8. ¿Considera que hay silencios } \\
\text { incómodos durante la exposición del } \\
\text { video? }\end{array}$ & 2.6 & 2.8 & 2.2 & 2.5 & $\begin{array}{l}\text { En desacuerdo } \\
\text { y } \\
\text { Ni de acuerdo ni } \\
\text { en desacuerdo }\end{array}$ \\
\hline $\begin{array}{l}\text { 9. ¿Le gustaría contar con más videos } \\
\text { que le apoyen con otros temas de este } \\
\text { curso? }\end{array}$ & 4.7 & 4.7 & 4.1 & 4.5 & De acuerdo \\
\hline $\begin{array}{l}\text { 10. ¿Compartiría este video con } \\
\text { alguien? }\end{array}$ & 4.4 & 4.3 & 3.8 & 4.1 & De acuerdo \\
\hline \multicolumn{4}{|c|}{ Promedio general } & 3.6 & De acuerdo \\
\hline
\end{tabular}

Fuente: Elaboración propia

En la tabla 8 también se aprecia el promedio general de los tres videos(es decir, 3.6), esto indica que la satisfacción de los estudiantes resultó estar entre los valores "ni de acuerdo ni en desacuerdo" y "de acuerdo", más cercano al último, lo cual se consideró por los expertos como una satisfacción apropiada.Sin embargo, en un trabajo futuro - para las actualizaciones de los videos o para la generación de otrossimilares - será necesario considerar la cantidad de información que se expone, así como revisar el número y momentos de los silencios empleados. 


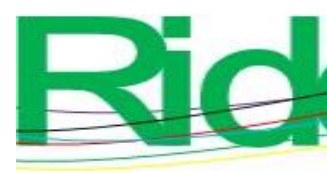

Revista Iberoamericana para la Investigación y el Desarrollo Educativo ISSN $2007-7467$

\section{Discusión de resultados}

A manera de autoevaluación, recopilación de experienciase identificación de mejores prácticas entre los autores de este documento y desarrolladores del OA-EAB, se enumera lo siguiente.

En cuanto al equipo de trabajo y su organización:

1. Es esencial la experiencia didáctica de los profesores de la FMexpertos en el curso, ya que ellos identificaroncuáles secciones de los temas requerían de mayor apoyo; es decir, sus modelos mentales, esquemas y bosquejos fueron indispensables para que los desarrolladores pudieran representar los contenidos en los videos. La participación de estudiantes de la FM durante el desarrollo del OA-EAB fue fundamental, dado que forman parte de la población de usuarios finales o audiencia a quienes está dirigido este objeto. En particular, en la fase de análisis y diseño, sucolaboración permitió ratificar las necesidades de formación y contribuir al diseño gráfico de los elementos que ayudaron a facilitar el aprendizaje. Al mismo tiempo, se reconoce el esfuerzo, compromiso y dedicación de los estudiantes colaboradores pertenecientes a la FCC, quienes invirtieron tiempo y esfuerzo para aprender la terminología de los temas seleccionados.

2. Una vez que se acordó el objetivo del OA-EAB, los profesores de ambas facultades trabajaron en varias sesiones los diferentes niveles de complejidad y el alcance temático, de forma que se transformara en un video con una duración considerable para mantener la atención de un estudiante promedio. Por otro lado, los estudiantes de la FCC-BUAP se enfocaron en representar en formato digital las representaciones tradicionales disponibles en libros, artículos y notas, tomando como ventaja que en el video estas representaciones tendrían cierto dinamismo.

3. Se requirió de la disponibilidad, dedicación y colaboración de todos los participantes para mantener una comunicación clara y constante que permitiera alcanzar el objetivo planteado.

4. Al inicio del proyecto, se elaboró un plan de trabajo que describía la duración de las actividades principales, los responsables y los productos esperados de cada actividad, así como las formas y mecanismos de seguimiento y control. Fue relevante haber considerado inicialmentelos tiempos para el diseño de los instrumentos y los momentos de aplicación. 


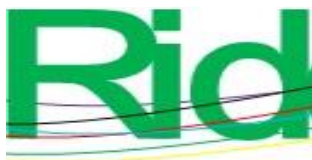
Revista Iberoamericana para la
Investigación y el Desarrollo Educativo
ISSN $2007-7467$

En cuanto a los resultados obtenidos, se puede percibir lo siguiente:

1. La cantidad de información que se incluye se considera adecuada, pero se debe poner atención en los silencios incómodos durante la exposición del video. Para esto último, quizás pueda reducirse el tiempo de exposición de alguna imagen, analizar si es necesario decir algo o definitivamente suprimir alguna imagen. Esto debe decidirse con ayuda de los expertos.

2. La relación entre el audio, las imágenes y el texto es adecuada, los textos resultan fácilmente legibles, las imágenes y animaciones presentadas son de buena calidad.

3. El video expone los temas a una velocidad adecuada, la pronunciación y entonación es entendible y los efectos de sonido se están utilizando adecuadamente; sin embargo, la calidad de estos aspectos pueden mejorarse, por ejemplo, cambiando la voz, modificando la velocidad del parlante o insertando efectos de sonido; según las preferencias y recomendaciones de los expertos.

4. La duración de los videos permitió mantener la atención de los estudiantes (ningún video resultó ser mayor a cinco minutos).

5. La inclusión de la lista de referencias al final de los videos fue bien recibida por los estudiantes.

6. Cabe destacar que $71 \%$ de los estudiantes que usaron los videos indicaron que entre sus mejores formas de aprender se incluye escuchando o viendo (es decir, eligieron escuchando-viendo-haciendo; escuchando-viendo; viendo-haciendo; viendo). Estos mismos estudiantes dijeron que les gustaría contar con más videos para otros temas del curso. Con respecto a $21.5 \%$ de los estudiantes que usaron los videos y que indicaron que su mejor forma de aprender es solamente haciendo, prácticamente el total de ellos indica que le gustaría contar con más videos que para apoyar otros temas del curso. Esto afirma que este tipo de recursos de apoyo al aprendizaje es bien aceptado por parte delos estudiantes, no importa la mejor forma que ellos tengan de aprender. 


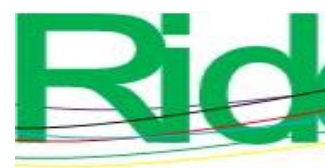

Revista Iberoamericana para la Investigación y el Desarrollo Educativo ISSN $2007-7467$

\section{Conclusiones}

El presente artículo presentó la evaluación de satisfacción de un OA diseñado para apoyar el aprendizaje de estudiantes de la licenciatura en Medicina. El contenido de este OA trata temáticas relacionadas con el equilibrio ácido-base, las cualesse exponen en tres videos elaboradoscon tecnologías de la información y comunicación,y distribuidos bajo los términos de políticas de acceso abierto.

Los videos se elaboraron en fases como análisis, diseño, desarrollo, implementación y evaluación. La colaboración y participación de estudiantes de medicina, estudiantes de computación, el conocimiento y experiencia de profesoresinvestigadores de la FM-BUAP y de la FCC-BUAP resultaron fundamentales en todas las fases. Este artículo presentó la metodología para estimar la evaluación de satisfacción de los videos producidos para el OA-EAB; los datos se recolectaron utilizando cuestionarios que fueron contestados por al menos 345 estudiantes pertenecientes a nueve cursos de Bioquímica I del primer semestre de la FM-BUAP. Los resultados indican un grado de satisfacción alto y señalan áreas de oportunidad para producir OA similares.

La elaboración de elementos multimedia en los cursos de instituciones de educación superior como el descrito en este documento está dirigida a influenciar de forma positiva los procesos de enseñanza-aprendizaje. Como trabajo futuro, se propone tomar en cuenta los resultados de la evaluación que salieron más bajos y buscar alternativas para su mejoría; por ejemplo, reducir el tiempo de los videos más largos, revisar los silencios incómodos para evitarlos, etc., todo siempre en colaboración con los expertos en el tema que se está abordando. Otra posibilidad sería crearlos en idioma inglés, así el alcance de estos podría ampliarse.

\section{Agradecimientos}

Este trabajo fue realizado gracias al apoyo del Proyecto VIEP-BUAP 2019 número 32, titulado Objeto de aprendizaje sobre los conceptos bioquímicos en el tema ácido base utilizando la plataforma Codaes. 


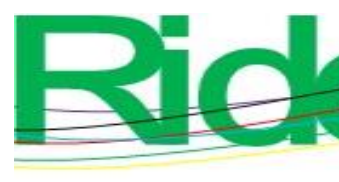

Revista Iberoamericana para la Investigación y el Desarrollo Educativo ISSN 2007-7467

\section{Referencias}

Aristizábal, S., Calvo, L. F., Valencia, L. A., Montoya-Canon, M., Barbosa-Gantiva, O. and Hincapié-Baena, V. (2015). Acid-base equilibrium: Thebestclinicalapproach. Revista Colombiana de Anestesiología, 43(3), 219-224. Recuperado de http://www.scielo.org.co/scielo.php?script=sci_arttext\&pid=S0120$33472015000300008 \& \operatorname{lng}=$ en $\&$ tlng=en.

Barrett, E., Barman, M., Boitano, S. and Brooks, L. (2018). Ganong Fisiología Médica. (25. ${ }^{\mathrm{a}}$ ed.). México: McGraw Hill Education.

Baynes, J. y Dominiczak, M. (2019). Bioquímica médica (4. ${ }^{a}$ ed.). España: Elsevier.

Cardozo, M. y Luciano, R. (2009a). Satisfacción estudiantil como indicador de calidad del proceso de enseñanza-aprendizaje en bioquímica: evaluación de la integración de la investigación a la asignatura. En I Jornadas Científicas y XXX Aniversario del Centro de Microscopía Electrónica Raúl García Arocha, Caracas, Venezuela.

Cardozo, M. y Luciano, R. (2009b). La investigación integrada al proceso de enseñanzaaprendizaje en bioquímica. En Memorias del 2009 VenezuelanDivisionMeeting (Porlamar, Venezuela) 126711.

Castillo, H., Zepeda, C., Cervantes, A., Carballido, J., Contreras, M., Archundia, E., Cerón, C., Rodríguez, M., Hernández, P., Martínez, M., Mendieta, V., Blasquez, M., Arévalo, M., Silva, P, Miranda, D., Monge, E. (2019). Objeto de aprendizaje para la enseñanza del tema equilibrio ácido-base en la licenciatura de Medicina. En Tovar, M., Zepeda, C. y Castillo, H. (eds.), Las entidades digitales educativas y sus aplicaciones (pp. 117-123). Puebla, México: Benemérita Universidad Autónoma de Puebla.

Comunidades Digitales para el Aprendizaje en Educación Superior [Codaes]. (2015). Objeto de aprendizaje [PDF file]. Recuperado de https://www.codaes.mx/content/micrositios/2/file/GuiaOA-CODAES.pdf

González, J., Montero, F. y Gutiérrez, F. (2012). Evolución del concepto de usabilidad como indicador de calidad del software. El profesional de la Información,21(5), $529-536$. Recuperado

de http://www.elprofesionaldelainformacion.com/contenidos/2012/septiembre/13.pdf 


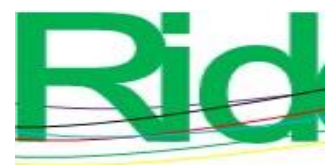

ISO 9241-11. 1998. Ergonomic requirements for office work with visual display terminals (VDTs) - Part 11: Guidance on usability.

Jardines, G. F. (2017). Revisión de los principales modelos de diseño instruccional. Innovaciones de Negocios, 8(16), 357-389. Recuperado de http://revistainnovaciones.uanl.mx/index.php/revin/article/view/143

Murray, R., Bender, D., Botham, K., Kennelly, P., Rodwell, V. y Weil, A. (2019). Harper Bioquímica Ilustrada. (3. ${ }^{\mathrm{a}}$ ed.). México: McGraw Hill Education.

Soledad, B., López, M. y Muñiz, R. (2017). El aporte de las tics en la enseñanza de la bioquimica. En Jornadas de Investigación, Tecnología Y Sociedad (JITS’17). Caracas, Venezuela.

Sowan, A. y Abu, J. (2014). Evaluation of an interactive web-based nursing course with streaming videos for medication administration skills. International Journal of Medical Informatics, 83(8), 592-600.

Velázquez, C., Rodríguez, F., Muñoz, J., Cardona, J., Silva. A., Hernández, Y. y Cechinel, C. (2014). Un estudio de la satisfacción obtenida con el uso de objetos de aprendizaje. En IX Conferencia Latinoamericana de Objetos de Aprendizaje y Tecnologías para el Aprendizaje. Manizales, Colombia. 


\begin{tabular}{|c|c|}
\hline Rol de Contribución & Autor (es) \\
\hline Conceptualización & $\begin{array}{l}\text { Claudia Zepeda Cortés, Ana Patricia Cervantes Márquez, Hilda } \\
\text { Castillo Zacatelco, José Luis Carballido Carranza, María del } \\
\text { Lurdez Consuelo Martínez Montaño, Patricia López Moreno, } \\
\text { Victoriano Mendieta Carmona, María Auxilio Medina Nieto } \\
\text { «igual» }\end{array}$ \\
\hline Metodología & $\begin{array}{l}\text { Claudia Zepeda Cortés, Ana Patricia Cervantes Márquez, Hilda } \\
\text { Castillo Zacatelco, José Luis Carballido Carranza, María del } \\
\text { Lurdez Consuelo Martínez Montaño, Patricia López Moreno, } \\
\text { Victoriano Mendieta Carmona, María Auxilio Medina Nieto } \\
\text { «igual» }\end{array}$ \\
\hline Software & $\begin{array}{l}\text { Claudia Zepeda Cortés, Ana Patricia Cervantes Márquez, Hilda } \\
\text { Castillo Zacatelco, José Luis Carballido Carranza } \\
\text { «igual» }\end{array}$ \\
\hline Validación & $\begin{array}{l}\text { Claudia Zepeda Cortés, Ana Patricia Cervantes Márquez, Hilda } \\
\text { Castillo Zacatelco, José Luis Carballido Carranza, María del } \\
\text { Lurdez Consuelo Martínez Montaño, Patricia López Moreno, } \\
\text { Victoriano Mendieta Carmona, María Auxilio Medina Nieto } \\
\text { «igual» }\end{array}$ \\
\hline Análisis Formal & $\begin{array}{l}\text { Claudia Zepeda Cortés, Ana Patricia Cervantes Márquez, Hilda } \\
\text { Castillo Zacatelco, José Luis Carballido Carranza, María del } \\
\text { Lurdez Consuelo Martínez Montaño, María Auxilio Medina } \\
\text { Nieto } \\
\text { «igual» }\end{array}$ \\
\hline Investigación & $\begin{array}{l}\text { Claudia Zepeda Cortés, Ana Patricia Cervantes Márquez, Hilda } \\
\text { Castillo Zacatelco, José Luis Carballido Carranza, María del } \\
\text { Lurdez Consuelo Martínez Montaño, Patricia López Moreno, } \\
\text { Victoriano Mendieta Carmona, María Auxilio Medina Nieto } \\
\text { «igual» }\end{array}$ \\
\hline Recursos & $\begin{array}{l}\text { Claudia Zepeda Cortés, Ana Patricia Cervantes Márquez, Hilda } \\
\text { Castillo Zacatelco, José Luis Carballido Carranza, María del } \\
\text { Lurdez Consuelo Martínez Montaño, Patricia López Moreno, } \\
\text { Victoriano Mendieta Carmona } \\
\text { «igual» }\end{array}$ \\
\hline Curación de datos & $\begin{array}{l}\text { Claudia Zepeda Cortés, Ana Patricia Cervantes Márquez, Hilda } \\
\text { Castillo Zacatelco, José Luis Carballido Carranza, María } \\
\text { Auxilio Medina Nieto } \\
\text { «igual» }\end{array}$ \\
\hline $\begin{array}{l}\text { Escritura - Preparación del } \\
\text { borrador original }\end{array}$ & Claudia Zepeda Cortés, María Auxilio Medina Nieto «igual» \\
\hline
\end{tabular}


